\title{
Design and Implementation of Computer Rank Examination System based on Winsock
}

\author{
Mao Zhuolin \\ Jiangxi College Of Foreign Studies
}

\begin{abstract}
Since the first electronic digital computer ENIAC born in University of Pennsylvania in 1946, people' $s$ life has completely changed because of computer. The application of computer has been all over the world. Computer technology is currently regarded as one of the three required technologies. In China, the application of computer started late, but with continuous drop of computer hardware' $s$ price, people' $s$ further understanding of computer technology, constant development of computer technology and promotion of national economy, the application of computer springs up and rapidly develops. Directing at problems and shortages of subjective questions in existing rank examination, this paper designs and develops a set of more practical computer rank examination system using the principle and method of software engineering after having an in-depth analysis and understanding of the working process of computer rank examination.
\end{abstract}

Keywords-Software engineering; Computer technology; Winsock

\section{INTRODUCTION}

The invention of computer was one of the greatest inventions in 20th century. The application of computer technology has changed people' s lifestyle and greatly promoted further development of human's science and technology. In the meantime, it also provides the most basic tool and means for the implementation of information era. More and more enterprises utilize computer technology to increase enterprise' s production efficiency, and more and more individuals use computer technology to enjoy the convenience and fastness brought by computer network. At the same time, more and more people join the trend of learning computer technology. Hence, computer application ability has become one of the most basic techniques and skills to assess contemporary people.

In order to adapt to the needs of social development, relevant departments of the country established specialized organizations to be in charge of the assessment of computer application technology ability, among which the most important ones are national computer rank examination and computer rank examination of various ministries of education. The number of participants of rank examination is increasing year by year, which explains that rank examination receives increasingly attention from people.

After analyzing and studying shortages of existing rank examination and development tendency of future rank examination system, this paper puts forward a solution for data transmission based on Winsock. Although this scheme hasn' $t$ met the requirement of total automation and total networking of future rank examination system, it solves shortages of existing rank examination system well.

\section{REQUIREMENT ANALYSIS OF COMPUTER RANK \\ EXAMINATION SYSTEM}

The task of software' s demand analysis is to confirm what jobs should the system complete and put forward complete, accurate, clear and specific requirements for system, mainly including system , $\mathrm{s}$ functional requirement, performance requirement, operating requirement and possible future requirements, etc. In the process of understanding and analyzing system requirements, it still requires developing prototype system to quicken understanding of the target system if lacking of understanding of the system requirements.

Requirement analysis is a software engineering activity, plays a critical role in the whole software' $s$ lifecycle and builds up the bridge of relationship between final user and software product. It is also the foundation of 
the development of the whole software project, so the quality of requirement analysis is directly related to customer satisfaction of software project' $s$ deliverables and even success or failure of the whole project.

In order to know users' data requirement and describe it correctly, it needs a useful tool to solve this problem. This tool is E-R figure.
In E-R figure, every frame represents entity, ellipse represents property and rhombus represents relevance. Through analysis of this system, it can obtain the E-R figure of this system:

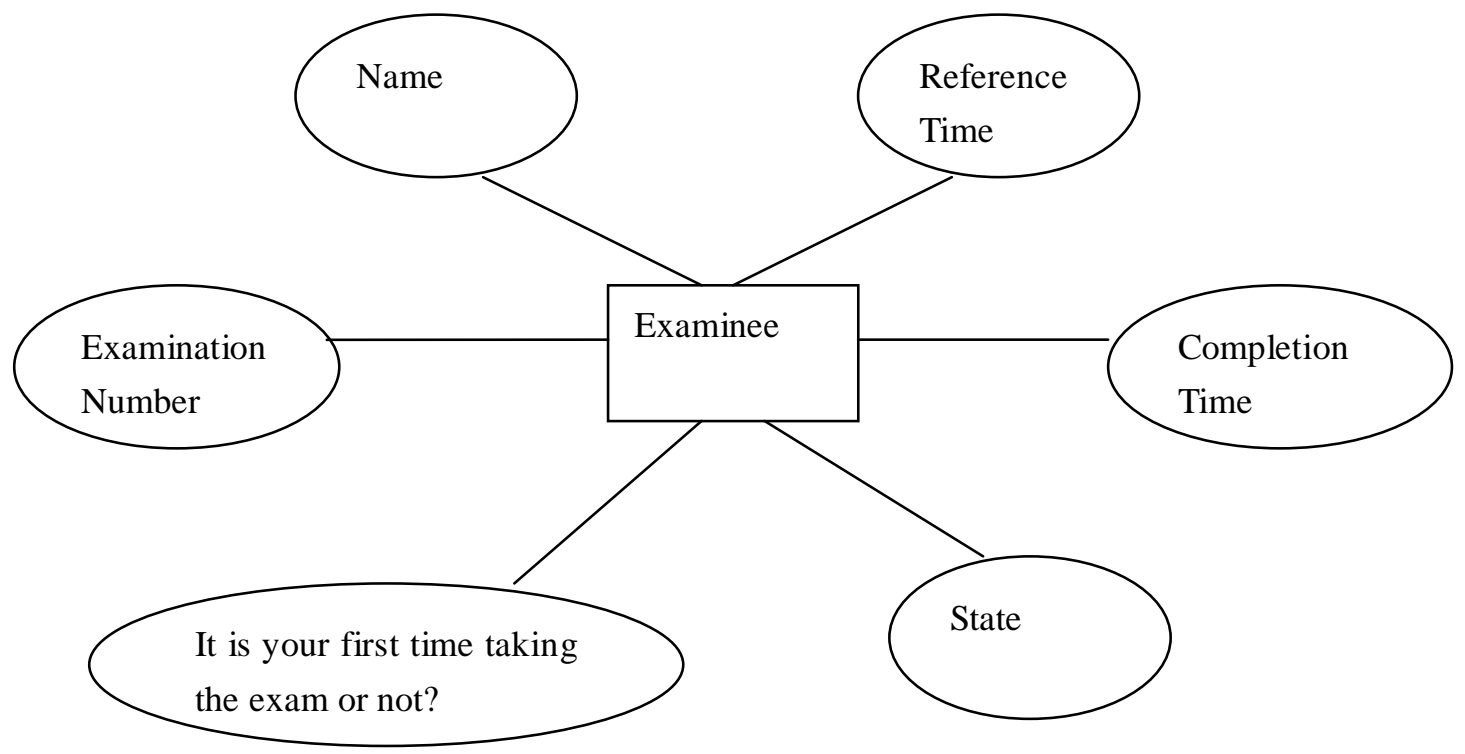

Figure 1. E-R Figure of the System

\section{COMMUNICATION THEORY OF WINSOCK}

Transmission of the data file in system is carried out through Winsock control, so here is the introduction of Winsock' $s$ communication mechanism. Implementing data communication through Winsock can be divided into following steps:

\section{A. Server intercepts network}

Since TCP is a connection-oriented agreement, it has to make connection preparation before data transmission. At this time, sever intercepts whether there is information from network at any time through methods like Listen.

\section{B. Client requests connection}

Client specifies the hostname (or IP) and port address to send out connection request to remote server through connect.

\section{Server allows connection request}

Server has two choices, one is allow request and the other is reject request. If it allows request, follow-up work can continue, or transmission of bilateral data is interrupted.

\section{File transfer}

When the connection is completed, data of both sides can be transferred. Transmitting end calls SendData and produces DataArrival event in server, and the needed file can be gained by calling GetData in this event. However, since they are transfer files rather than ordinary characters, it has to place files to array and then read file and write file from data.

\section{E. Close connection}

Close connection aims to release resources (port) that both sides occupy to make sure those resources can be used by other routines.

Its workflow is showed as Figure 2. 


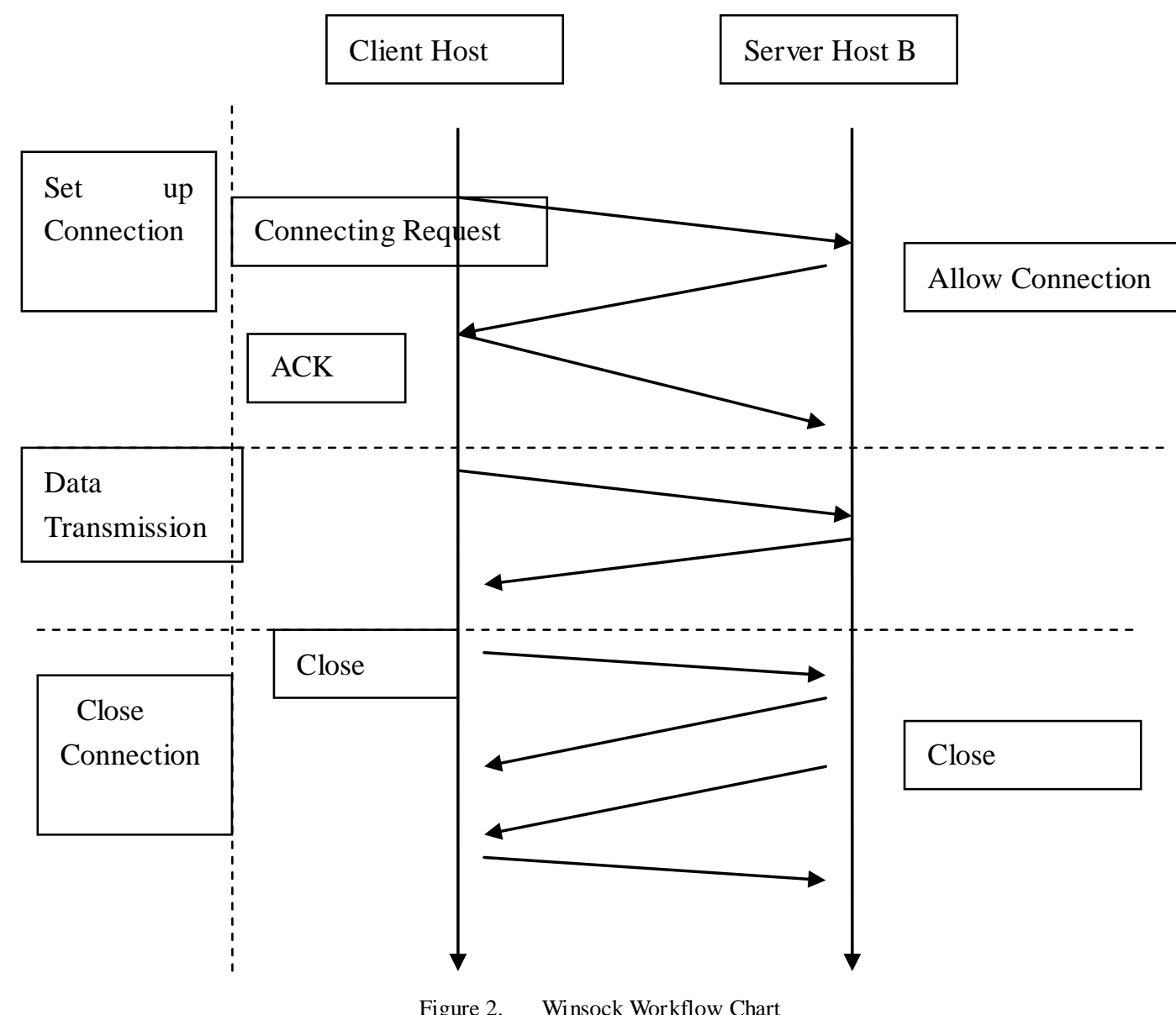

\section{OVERALL DESIGN OF COMPUTER RANK EXAMINATION SYSTEM}

System design is the working achievement based on requirement analysis and obtains a series of effective system implementation schemes through making an in-depth analysis of the system to implement the whole system logically and physically. System design is the key stage of software project' s implementation. Quality of the design directly determines whether the software project is a success or not. The purpose of overall design is to solve the problem of how to do the system and its design criteria mainly include following aspects:
1. Increase module' $\mathrm{s}$ independence as far as possible

2. Choose appropriate scale of the module

3. Depth, width, fan-in and fan-out of the module should be appropriate

4. The range of action of module should be within controllable range

Pattern description tools used in the overall design process mainly include hierarchy chart, HIPO chart and structure chart.

Hierarchy chart is used to describe software' s hierarchy structure. One hierarchy represents a function module and lines among frames represent the relationship of calling each other. 


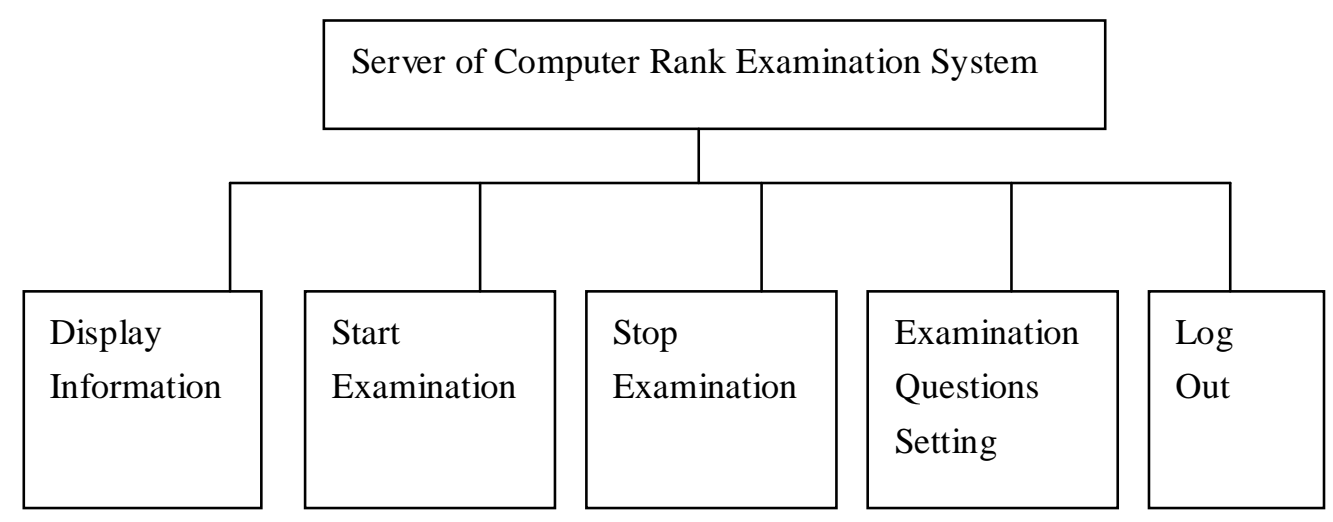

Figure 3. Hierarchy Chart of System Server

\section{CONCLUSION}

Following conclusions are drawn based on descriptions above:

\section{A. Implement examination questions, automation in uploading and downloading}

This is the basic function of system. It can download examination questions from server to examinee computer in time, open examination questions and open examination environment to help examinee take part in the examination successfully. It can also upload examination questions to server conveniently after examinees finish the exam to reduce teachers' workload.

\section{B. Effectively implement fast switch of examination questions}

Set the file mode of examination questions in server to rapidly switch every batch of examinees' examination files and eventually achieve the goal of difference in different batches of examinees' examination files. Simple setting can help reduce original workload by switching examination questions through ways like making disk or network sharing.

\section{Timely understand examinees' examination situation}

Original examination can' $\mathrm{t}$ fully understand examinees , examination situation in different examination rooms. Application of this system can conveniently understand examinees, information in every examination.

Application of this system effectively increases invigilators, work efficiency, reduces teachers, workload, regulates the examination process and has higher practical use and realistic significance to the implementation of online computer rank examination.

\section{REFERENCES}

[1] Khan R A, Agrawal A. Software Engineering: A Practitioners Approach[M]// Alpha Science International, 2014

[2] Jennings $\mathrm{N}$ R, Wooldridge $\mathrm{M}$. On agent-based software engineering[J]. Artificial Intelligence, 2000, 117(1):277-296.

[3] Brooks, Frederick P. "No Silver Bullet: Essence and Accidents of Software Engineering." IEEE Computer 1987:10-19.

[4] IEEE. IEEE Standard Glossary of Software Engineering Terminology: IEEE[C]// IEEE Std. 1990.

[5] Humphrey W S. A discipline for software engineering[M]// Addison-Wesley, 1995:1-3.

[6] Petrie C. Agent-based software engineering[J]. IEE Proceedings Software Engineering, 1997, 144(1):26--37.

[7] Humphrey H W S. A Discipline for Software Engineering, ISBN 0-201-54610-8[J]. Sei, 1995, 30(3):1-3.

[8] Wohlin C, Runeson P, Höst M, et al. Experimentation in Software Engineering[J]. IEEE Trans Soft Eng, 2009, se-12(7):1-16.

[9] Garlan, D., and M. Shaw. "An introduction to software architecture: advances in software engineering and knowledge engineering." Advances in Software Engineering \& Knowledge Engineering 44Part2(1993):1--39.

[10] Jazayeri M, Tu W. Fundamentals of Software Engineering[J]. Lecture Notes in Computer Science, 1991, 9392:2433-2434.

[11] Kitchenham B /, Pfleeger S L, Pickard L M, et al. Preliminary guidelines for empirical research in software engineering. IEEE Trans Softw Eng[J]. IEEE Transactions on Software Engineering, 2002, 28(8):721-734

[12] Basili V R, Weiss D M. A Methodology for Collecting Valid Software Engineering Data.[J]. Software Engineering IEEE Transactions on, 1984, se-10(6):728-738 